\title{
Fountain syndrome
}

INSERM

\section{Source}

INSERM. (1999). Orphanet: an online rare disease and orphan drug data base. Fountain syndrome. ORPHA:3219

Fountain syndrome is an extremely rare multi-systemic genetic disorder characterized by intellectual disability, deafness, skeletal abnormalities and coarse facial features. 